"This is the peer reviewed version of the following article: ChemSusChem 2017, 10, 1274-1282, which has been published in final form at DOI: $10.1002 /$ cssc.201601712. This article may be used for non-commercial purposes in accordance with Wiley Terms and Conditions for Self-Archiving published at http://olabout.wiley.com/WileyCDA/Section/id-820227.html." 


\title{
Aluminum-Mediated Formation of Cyclic Carbonates: Benchmarking Catalytic Performance Metrics
}

\author{
Jeroen Rintjema, ${ }^{[a]}$ and Arjan W. Kleij ${ }^{*[a][b]}$
}

\begin{abstract}
We report a comparative study on the activity of a series of five binary catalysts derived from various reported aluminum-based complexes. A benchmarking of their initial rates in the coupling of various terminal and internal epoxides in the presence of three different nucleophilic additives has been carried out providing for the first time a useful comparison of activity metrics in the area of cyclic organic carbonate formation. These investigations provide a useful framework how to realistically valorize relative reactivities and which features are important to consider the ideal operational window of each binary catalyst system.
\end{abstract}

\section{Introduction}

The conversion and activation of small molecules such as carbon dioxide $\left(\mathrm{CO}_{2}\right)$ is among the most active fields in modern research. ${ }^{[1]}$ Typically, catalysis has proven to be a key enabling technology for the conversion of $\mathrm{CO}_{2}$ into organic molecules with a higher degree of complexity as it allows to reduce the high kinetic barrier of breaking the rather inert $\mathrm{C}=\mathrm{O}$ bonds. ${ }^{\left[{ }^{[2]}\right.}$ Additionally, an energy input is required to thermodynamically facilitate $\mathrm{CO}_{2}$ conversion, and co-reactants with a relative high free energy such as strained heterocycles, ${ }^{[3]}$ and reducing agents including hydrogen, ${ }^{[4]}$ silanes and boron compounds ${ }^{[5]}$ have been classically used. In all cases, catalyst selection, development and optimization is paramount to achieve the best performance in terms of selectivity and/or activity.

One of the most widely studied reactions in $\mathrm{CO}_{2}$ catalysis is undoubtedly the formation of cyclic organic carbonates (COCs), ${ }^{[6]}$ and some of these have been commercialized. ${ }^{[7]}$ Both metalbased $^{[8]}$ as well as organocatalytic approaches ${ }^{[9]}$ have become popular to mediate the coupling between epoxides and $\mathrm{CO}_{2}$ and discovery of new catalysts continues to draw broad attention from the scientific communities. Much less explored is the development of new reactivity that aims at the discovery of new/improved selectivity, ${ }^{[10]}$ increasing the overall reactivity (including efforts towards more sustainable reaction conditions) ${ }^{[11]}$ and amplification of the substrate portfolio to provide new

\footnotetext{
[a] J. Rintjema, Prof. Dr. A. W. Kleij Institute of Chemical Research of Catalonia (ICIQ)

The Barcelona Institute of Science and Technology Av. Països Catalans 16, 43007 Tarragona (Spain) E-mail: akleij@iciq.es

[b] Prof. Dr. A. W. Kleij

Catalan Institute of Research and Advanced Studies (ICREA) Pg. Lluís Companys 23, 08010 Barcelona (Spain)
}

Supporting information for this article is given via a link at the end of the document. opportunities in synthetic and polymer chemistry. ${ }^{[12]}$ Particularly relevant for potential commercial applications is the design of catalysts that can combine low toxicity and cost, easy handling, abundance, modular features and high activity. In this context, various groups have focused on the use of Fe- ${ }^{[13]} \mathrm{Zn}-{ }^{[14]}$ and $\mathrm{Al}-$ based catalysts ${ }^{[15]}$ that generally display catalytic performances that are among the best reported to date. For example, Ema et al. reported on highly active bifunctional $\mathrm{Zn}$ (porphyrin) catalysts with high turnover numbers at elevated temperatures $\left(120-160^{\circ} \mathrm{C}\right) .{ }^{[16]}$ More recently the same authors described a synergistic (theoretical) model explaining the cooperation between the Lewis acid site and peripheral ammonium halide groups that serve as nucleophiles. ${ }^{[17]}$
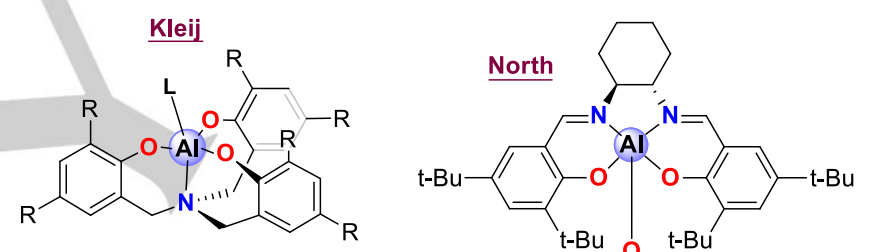

$$
\begin{aligned}
& \text { 1a, }[\mathrm{Al}]^{\mathrm{Cl}}: \mathrm{R}=\mathrm{Cl} ; \mathrm{L}=\text { thf } \\
& \text { 1b, }[\mathrm{AI}]^{\mathrm{Me}}: \mathrm{R}=\mathrm{Me} ; \mathrm{L}=\text { thf }
\end{aligned}
$$$$
\text { 1c, }[\mathrm{Al}]^{\mathrm{tBu}}: \mathrm{R}=t \mathrm{Bu} ; \mathrm{L}=\text { thf }
$$
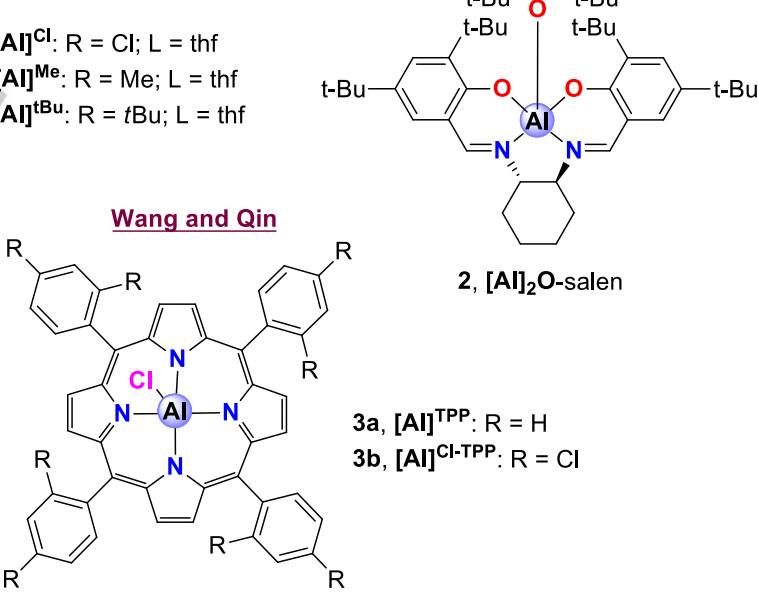

Figure 1. Three different types of $\mathrm{Al}(\mathrm{III})$ complexes used as components of highly active binary catalysts: Kleij's aminotriphenolate 1, North's bimetallic salen system 2 and Wang/Qin's porphyrin-based complex $\mathbf{3}$.

However, a direct comparison between (binary/bifunctional) catalysts active towards the formation of COCs remains difficult as many systems incorporate different metal centers, are based on different ratios between metallic and nucleophilic sites, are operated under different reaction conditions (temperature, pressure) and catalytic performances are often determined in different reactor systems. These differences often render claims 
of high(est) reactivity unsuitable to serve as absolute reference points. Therefore, benchmarking relative performances under identical conditions can help to further determine the impact of a given catalyst in the context of $\mathrm{COC}$ synthesis by carefully examining the influence of substrate, reaction conditions and catalyst composition. In this respect, a recent comparative study on the influence of different hydrogen-bond donor systems on the overall activity of binary catalysts in the conversion of propylene oxide and $\mathrm{CO}_{2}$ into its cyclic carbonate derivative has shown the importance of benchmarking, and revealed that fluorinated alcohols explicitly are highly potent catalyst components. ${ }^{[18]}$

Here we report on a detailed comparison between a preselected series of Al-based binary catalysts (Figure 1) and have assessed their initial reactivity towards six different epoxide partners. Our results discussed herein clearly demonstrate that the different operative mechanistic manifolds are crucial for the catalyst performance. Specifically, the nature and amount of the nucleophile, the operating reaction temperatures and concentration of the binary couples are important parameters that define the overall reactivity and the most suitable operation window for each binary catalyst system. This information should be carefully considered depending on the type of epoxide $/ \mathrm{CO}_{2}$ coupling reaction that is of interest.

\section{Results and Discussion}

\section{Reactivity towards Terminal Epoxide Conversion}

The complexes illustrated in Figure 1 (1-3) were tested under identical reaction conditions in a parallel reactor system (see Supporting Information for details). For comparison also the mono-metallic $\mathrm{Al}($ salen) $\mathrm{Cl}$ complex 4 was included in these studies. In order to examine the reactivities of the complexes 1-4 upon combination with various nucleophiles, initial kinetics were determined in most of the following cases reported here. First, the conversion of three different terminal epoxides $(\mathbf{A}-\mathbf{C})$ was investigated at $90^{\circ} \mathrm{C}, 10$ bar and at low complex loading $([\mathrm{Al}]=$ $0.01 \mathrm{~mol} \%)$, see Tables 1 and 2. ${ }^{[19]}$ As co-catalytic nucleophiles tetrabutylammonium halides (TBA-X; $X=\mathrm{Br}, \mathrm{I})$ and bis(triphenylphosphine)iminium chloride $(\mathrm{PPNCl})^{[20]}$ were used in a five-fold excess with respect to the Al complex.

The conversion of 1,2-epoxyhexane $\mathbf{A}$ (Table 1) and total turnover numbers (TONs) were determined for all binary combinations after $2 \mathrm{~h}$ on a per reactive center basis, i.e. per Al site. The data were compared within each series with the background conversion mediated by the nucleophilic additive alone as a reference (entries 1, 7 and 13). Striking differences were noted for the binary systems based on 1-4, as well as significant changes upon variation of the type of nucleophile (halide). In the presence of PPNCl as nucleophile (entries 1-6), the data clearly demonstrate that the Wang and Qin complex $\mathbf{3 b}$ has excellent activity under these conditions (entry 5), in line with their previous findings. ${ }^{[11 \mathrm{c}]}$ Interestingly, the non-chlorinated version of this $\mathrm{Al}$ (porphyrin) based binary catalyst (Figure 1, 3a; entry 4) displays similar activity features suggesting that Lewis acidity for this system under dilute catalyst conditions does not play an imperative role. Apart from $\mathbf{3 b}$, the Kleij system based on 1a shows significantly better activity compared to the other screened binary catalysts that are derived from $\mathbf{2}$ and $\mathbf{4}$.

Table 1. Comparison of the reactivities of binary Al-catalysts $1-4 / X(X=C l$, $\mathrm{Br}, \mathrm{I})$ in the conversion of terminal epoxide $\mathbf{A}$ into the cyclic carbonate 5. $^{[\mathrm{a}]}$

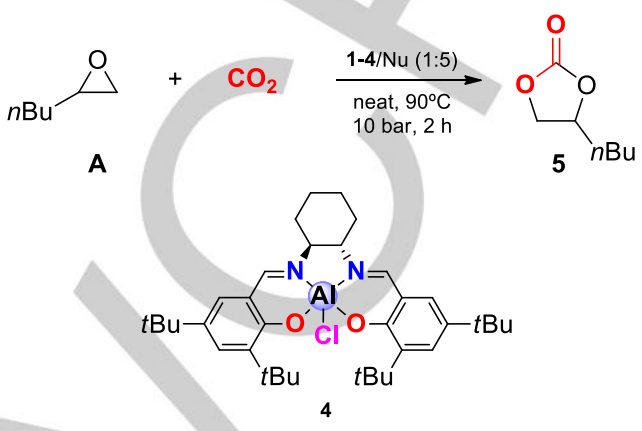

\begin{tabular}{|c|c|c|c|c|c|}
\hline Entry & Cat & $\mathrm{Nu}$ & Substrate & Yield [\% $]^{[b]}$ & TON $[c]$ \\
\hline 1 & - & PPNCl & A & 3 & - \\
\hline 2 & $1 a$ & PPNCl & A & 14 & 1400 \\
\hline 3 & 2 & PPNCl & A & 5 & 250 \\
\hline 4 & $3 a$ & PPNCl & A & 35 & 3500 \\
\hline 5 & $3 b$ & PPNCl & A & 33 & 3300 \\
\hline 6 & 4 & PPNCl & A & 4 & 400 \\
\hline 7 & - & TBAB & A & 1 & - \\
\hline 8 & $1 a$ & TBAB & A & 19 & 1900 \\
\hline 9 & 2 & TBAB & A & 3 & 150 \\
\hline 10 & $3 a$ & TBAB & A & 11 & 1100 \\
\hline 11 & $3 b$ & TBAB & A & 12 & 1200 \\
\hline 12 & 4 & TBAB & A & 3 & 300 \\
\hline 13 & - & TBAI & A & 2 & - \\
\hline 14 & $1 a$ & TBAI & A & 13 & 1300 \\
\hline 15 & 2 & TBAI & A & 2 & 100 \\
\hline 16 & $3 a$ & TBAI & A & 7 & 700 \\
\hline 17 & $3 b$ & TBAI & A & 7 & 700 \\
\hline 18 & 4 & TBAI & A & 3 & 300 \\
\hline
\end{tabular}

[a] Reaction conditions: epoxide A $(10.0 \mathrm{mmol})$, Al-complex $(0.001 \mathrm{mmol}$; $0.01 \mathrm{~mol} \%$ ), nucleophile ( $\mathrm{Nu}$ : $0.005 \mathrm{mmol} ; 0.05 \mathrm{~mol} \%)$, mesitylene (1.0 $\mathrm{mmol}), 90^{\circ} \mathrm{C}, 10$ bar, $2 \mathrm{~h}$; [b] Determined by ${ }^{1} \mathrm{H} \mathrm{NMR}\left(\mathrm{CDCl}_{3}\right)$ using mesitylene as internal standard; the average of two runs is reported. Selectivity towards the cyclic carbonate $\mathbf{5}$ was $>99 \%$. [c] TON = total turnover number observed per Al center; note that complex 2 contains two Al centers.

A dramatic change in the activity order was observed when changing the nucleophile from PPNCI to TBAB and TBAI (entries 
7-18). In the presence of both TBAB and TBAl the most active binary catalyst is the one based on complex $1 \mathbf{a}$, followed by the porphyrin systems $3 a / T B A X$ and $3 b / T B A X(X=B r, I)$. Binary couple 1a/TBAB shows the highest TON (entry $8 ; 1900$ ) under these conditions and these observations align well with previous data in the literature that showed that bromide based nucleophiles give the highest activities when combined with $\mathrm{Al}$ (aminotriphenolate) complexes. ${ }^{[11 \mathrm{a}]}$

Table 2. Comparison of the reactivities of binary Al-catalysts $1-4 / \mathrm{Nu}$ in the conversion of terminal epoxides $\mathbf{B}$ and $\mathbf{C}$ into their respective cyclic carbonates 6 and 7 . $^{\text {a] }}$

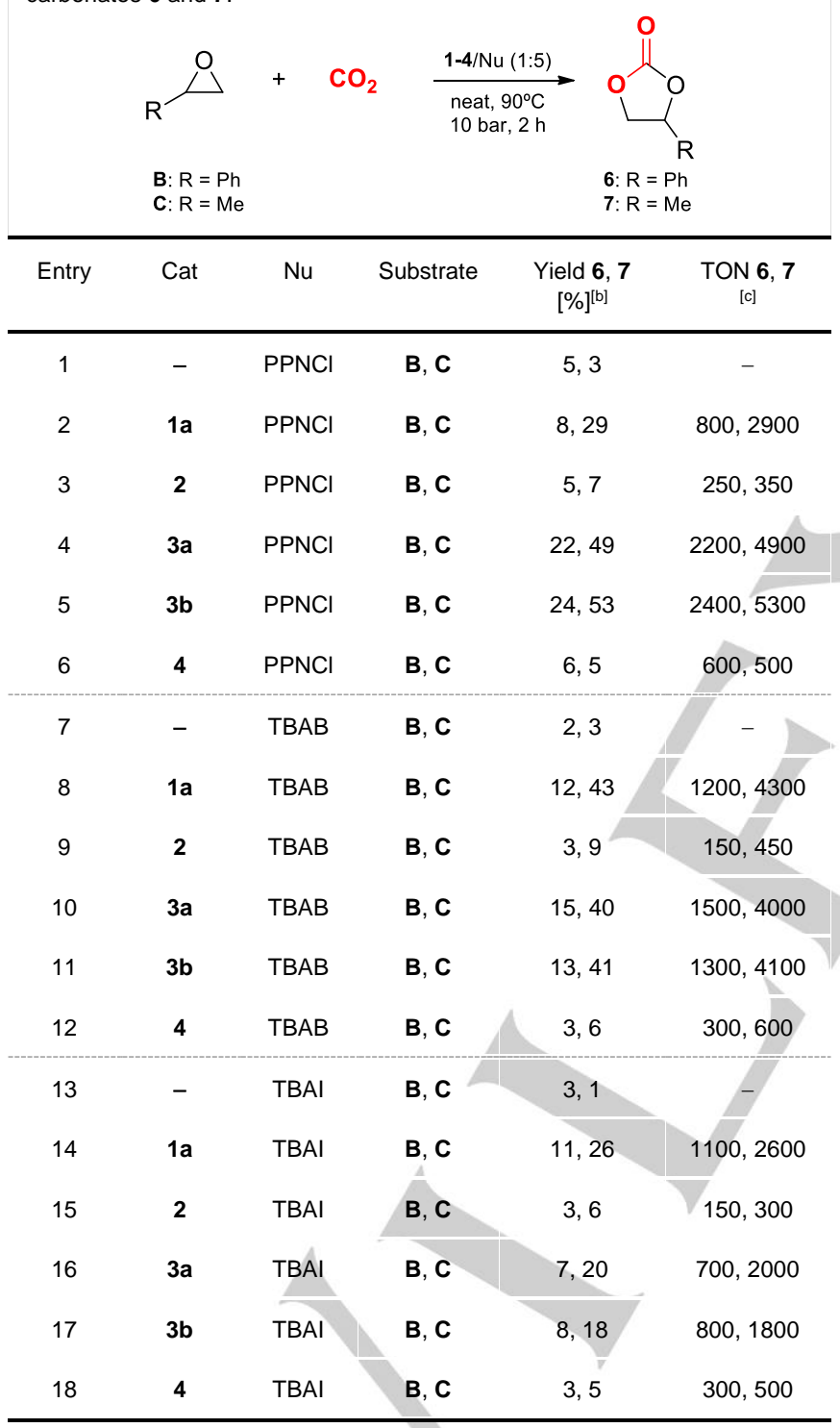

[a] Reaction conditions: epoxide B or C (10.0 mmol), Al-complex (0.001 $\mathrm{mmol} ; 0.01 \mathrm{~mol} \%)$, nucleophile ( $\mathrm{Nu}: 0.005 \mathrm{mmol} ; 0.05 \mathrm{~mol} \%)$, mesitylene (1.0 $\mathrm{mmol}), 90^{\circ} \mathrm{C}, 10$ bar, $2 \mathrm{~h}, \mathrm{Nu}=$ nucleophile; [b] Determined by ${ }^{1} \mathrm{H}$ NMR $\left(\mathrm{CDCl}_{3}\right)$ using mesitylene as internal standard, first number refers to yield when using B as substrate; the average of two runs is reported. Selectivity towards the cyclic carbonates 6 and 7 was $>99 \%$. [c] TON = total turnover number observed per Al; note that complex 2 contains two Al centers.
Additionally, a similar reactivity difference between catalysts based on 1a and the North system $\mathbf{2}$ has been observed at a tenfold higher loading of both catalyst components $(0.01 \mathrm{~mol} \%$ [Al], $0.05 \mathrm{~mol} \% \mathrm{TBAI}) .{ }^{[15 \mathrm{c}]}$ The combined results for the conversion of terminal epoxide $\mathbf{A}$ into mono-substituted cyclic carbonate $\mathbf{5}$ (Table 1) suggest that matching of the Lewis acid complex and nucleophilic additive has a pronounced influence on the overall catalyst performance.

Intrigued by the results presented in Table 1, we then decided to screen two other terminal epoxides to see whether the trends observed in the catalytic formation of cyclic carbonate $\mathbf{5}$ from terminal epoxide $\mathbf{A}$ were of a more general nature (see Table 2). Indeed, when all results are considered it can be observed that also in the conversion of styrene oxide (B) and propylene oxide (C) in the presence of PPNCl as nucleophilic additive, both porphyrin based binary systems $3 a / P P N C l$ and $3 b / P P N C l$ have significantly higher activities compared to the other binary catalysts derived from 1, 2 and 4 (Table 2, entries 1-6). After combining complexes 1-4 with either TBAB or TBAI, the activities noted in the presence of $\mathbf{3} \mathbf{a}$ and $\mathbf{3} \mathbf{b}$ drop whereas those for the systems based on 1a specifically become more competitive and reveal similar to slightly improved activities (entries 8 and 14) as noted for the binary combinations comprising of metalloporphyrins $\mathbf{3 a}$ or $\mathbf{3 b}$.

The somewhat lower conversion kinetics for the styrene oxide substrate compared to 1,2-epoxyhexane and propylene oxide is likely a result of electronic effects as reported previously. ${ }^{[21]}$ This affects the nucleophilic character of the alkoxide intermediate after initial ring-opening of the epoxide via a more pronounced charge delocalization. Overall, the results of Tables 1 and 2 align well and show clear reproducible trends in the initial conversion kinetics of terminal epoxides and $\mathrm{CO}_{2}$ at $90^{\circ} \mathrm{C}$ catalyzed by binary catalysts derived from Al-complexes 1-4.

\section{Influence of Reaction Temperature}

Our next focus was on the influence of the reaction temperature on the catalyst performance and therefore parallel catalysis experiments were performed at 25,50 and $105^{\circ} \mathrm{C}$ in a suitable high-throughput reactor platform (Supporting Information for details; see Table 3). TBAB was used as nucleophile as most of the catalysts studied here showed appreciable turnover in the presence of this additive. At ${ }^{2}{ }^{\circ} \mathrm{C}$ (entries $\left.1-8\right)$, the two porphyrin based catalysts show the best performance with in both cases (entries 6 and 7) nearly quantitative or quantitative conversion, and high turnover numbers. Under these conditions, the North system 2/TBAB also performs comparatively well (entry 5) whereas the aminotriphenolate complexes 1a-1c show lower activity (entries 2-4). Upon raising the reaction temperature to $50^{\circ} \mathrm{C}$ (entries 9-16), the most notable changes are observed for the binary systems based on $\mathbf{1 a - 1 c}$, with the combination of Alcomplex 1a and TBAB (entry 10) now being the third most efficient catalyst. The results obtained at $105^{\circ} \mathrm{C}([\mathrm{Al}]=0.001 \mathrm{~mol} \%$, TBAB $=0.005 \mathrm{~mol} \%$ ) reveal that at elevated temperatures the binary combination 1a/TBAB shows the best catalytic turnover (entry 
Table 3. Comparison of the reactivities of binary Al-catalysts 1-4/TBAB in the conversion of terminal epoxide $\mathbf{A}$ into cyclic carbonate $\mathbf{5}$ at different reaction temperatures. ${ }^{[a]}$

\begin{tabular}{|c|c|c|c|c|c|}
\hline Entry & Cat & $\mathrm{Nu}$ & $\mathrm{T}\left[{ }^{\circ} \mathrm{C}\right]$ & Yield [\%] $]^{[b]}$ & $\mathrm{TON}^{[\mathrm{c}]}$ \\
\hline 1 & - & TBAB & 25 & $<1$ & - \\
\hline 2 & $1 a$ & TBAB & 25 & 19 & 190 \\
\hline 3 & $1 b$ & TBAB & 25 & 13 & 130 \\
\hline 4 & 1c & TBAB & 25 & 19 & 190 \\
\hline 5 & 2 & TBAB & 25 & 30 & 150 \\
\hline 6 & $3 a$ & TBAB & 25 & 97 & 970 \\
\hline 7 & $3 b$ & TBAB & 25 & $>99$ & 1000 \\
\hline 8 & 4 & TBAB & 25 & 18 & 180 \\
\hline 9 & - & TBAB & 50 & 2 & - \\
\hline 10 & $1 a$ & TBAB & 50 & 63 & 630 \\
\hline 11 & $1 b$ & TBAB & 50 & 43 & 430 \\
\hline 12 & 1c & TBAB & 50 & 38 & 380 \\
\hline 13 & 2 & TBAB & 50 & 49 & 245 \\
\hline 14 & $3 a$ & TBAB & 50 & 96 & 960 \\
\hline 15 & $3 b$ & TBAB & 50 & 97 & 970 \\
\hline 16 & 4 & TBAB & 50 & 36 & 360 \\
\hline 17 & - & TBAB & 105 & 6 & - \\
\hline 18 & $1 a$ & TBAB & 105 & 76 & 3800 \\
\hline 19 & $1 b$ & TBAB & 105 & 47 & 2350 \\
\hline 20 & 1c & TBAB & 105 & 51 & 2550 \\
\hline 21 & 2 & TBAB & 105 & 12 & 300 \\
\hline 22 & $3 a$ & TBAB & 105 & 44 & 2200 \\
\hline 23 & $3 b$ & TBAB & 105 & 52 & 2600 \\
\hline 24 & 4 & TBAB & 105 & 8 & 400 \\
\hline
\end{tabular}

[a] Reaction conditions at $\mathbf{2 5}$ and $\mathbf{5 0}$ - C: epoxide $\mathbf{A}(5.0 \mathrm{mmol}), \mathrm{Al}$-complex (0.005 mmol; $0.1 \mathrm{~mol} \%)$, nucleophile ( $\mathrm{Nu}: 0.025 \mathrm{mmol} ; 0.5 \mathrm{~mol} \%)$, mesitylene $(0.5 \mathrm{mmol}), 10 \mathrm{bar}, 8 \mathrm{~h}\left(25^{\circ} \mathrm{C}\right)$ and $3 \mathrm{~h}\left(50^{\circ} \mathrm{C}\right)$; Reaction conditions at $105^{\circ} \mathrm{C}$ : epoxide A $(5.0 \mathrm{mmol})$, Al-complex ( $0.001 \mathrm{mmol} ; 0.02 \mathrm{~mol} \%)$, nucleophile ( $\mathrm{Nu}$ : $0.005 \mathrm{mmol} ; 0.1 \mathrm{~mol} \%)$, mesitylene $(0.5 \mathrm{mmol}), 10 \mathrm{bar}, 2 \mathrm{~h}$. [b] Determined by ${ }^{1} \mathrm{H}$ NMR $\left(\mathrm{CDCl}_{3}\right)$ using mesitylene as internal standard; the average of two runs is reported. Selectivity towards the cyclic carbonate 5 was $>99 \%$. [c] TON = total turnover number observed per $\mathrm{Al}$; note that complex 2 contains two Al centers.
Table 4. Comparison of the reactivities of binary Al-catalysts $1-4 / \mathrm{Nu}$ in the conversion of internal epoxide $\mathbf{D}-\mathbf{F}$ into cyclic carbonates $\mathbf{8 - 1 0}$ at $90^{\circ}$. [a]
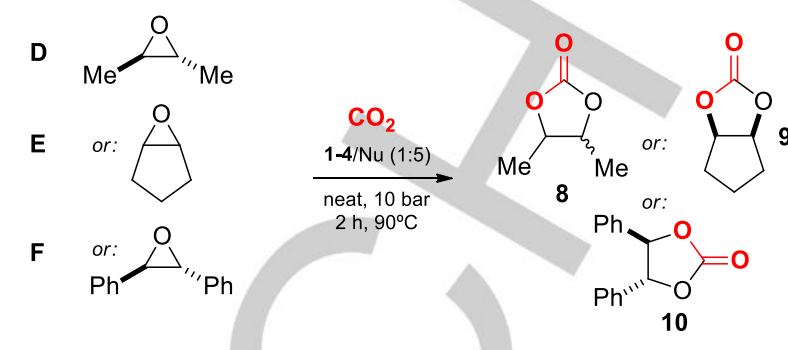

\begin{tabular}{|c|c|c|c|c|c|c|}
\hline Entry & Cat & $\mathrm{Nu}$ & Sub & $\begin{array}{l}\text { Yield } \\
{[\%]^{[\mathrm{b}]}}\end{array}$ & $\underset{[c]}{\text { TON }}$ & $\begin{array}{l}\text { Sel. } \\
{[\%]^{[d]}}\end{array}$ \\
\hline
\end{tabular}

$\begin{array}{ccccccc}1^{[\mathrm{e}]} & - & {[\mathbf{C l}] /[\mathrm{Br}]} & \mathbf{D} & <1,<1 & - & \text { ND } \\ 2^{[\mathrm{e}]} & \mathbf{1 a} & {[\mathbf{C l}] /[\mathrm{Br}]} & \mathbf{D} & 8,12 & 200,300 & >99 \\ 3^{[\mathrm{e}]} & \mathbf{2} & {[\mathbf{C l}] /[\mathrm{Br}]} & \mathbf{D} & 1,1 & 13,13 & >99 \\ 4^{[\mathrm{e}]} & \mathbf{3 a} & {[\mathbf{C l}] /[\mathrm{Br}]} & \mathbf{D} & 5,3 & 125,75 & >99\end{array}$

\begin{tabular}{|ccccccc}
$4^{[\mathrm{e}]}$ & 3a & {$[\mathbf{C l}] /[\mathrm{Br}]$} & D & 5,3 & 125,75 & $>99$ \\
$5^{[\mathrm{e}]}$ & 3b & {$[\mathbf{C l}] /[\mathrm{Br}]$} & D & 13,10 & 325,250 & $24: 76^{[\mathrm{f}]}$ \\
& & & & & & $7: 93^{[\mathrm{g}]}$
\end{tabular}

$6^{[\text {e] }} \quad 4 \quad[\mathrm{Cl}] /[\mathrm{Br}] \quad \mathbf{D} \quad 1,1 \quad 25,25 \quad>99$

$7-\quad[\mathbf{C l}] /[\mathrm{Br}] \quad \mathbf{E} \quad 4,2 \quad-\quad$ ND

\begin{tabular}{ccccccc}
8 & $\mathbf{1 a}$ & {$[\mathbf{C l}] /[\mathrm{Br}]$} & $\mathbf{E}$ & 12,19 & 300,475 & $>99$ \\
9 & $\mathbf{2}$ & {$[\mathbf{C l}] /[\mathrm{Br}]$} & $\mathbf{E}$ & 6,6 & 75,75 & $>99$ \\
10 & $\mathbf{3 a}$ & {$[\mathbf{C l}] /[\mathrm{Br}]$} & $\mathbf{E}$ & 36,15 & 900,375 & $>99$ \\
11 & $\mathbf{3 b}$ & {$[\mathbf{C l}] /[\mathrm{Br}]$} & $\mathbf{E}$ & 37,15 & 925,375 & $>99$ \\
\hline 12 & $\mathbf{4}$ & {$[\mathbf{C l}] /[\mathrm{Br}]$} & $\mathbf{E}$ & 5,4 & 125,100 & $>99$ \\
13 & - & {$[\mathbf{C l}] /[\mathrm{Br}]$} & $\mathbf{F}$ & $1,1^{[\mathrm{h}]}$ & - & $N$ \\
14 & $\mathbf{1 a}$ & {$[\mathbf{C l}] /[\mathrm{Br}]$} & $\mathbf{F}$ & $6,21^{[\mathrm{h}]}$ & 10,35 & $>99$ \\
15 & $\mathbf{2}$ & {$[\mathbf{C l}] /[\mathrm{Br}]$} & $\mathbf{F}$ & $5,8^{[\mathrm{h}]}$ & 4,7 & $>99$ \\
16 & $3 \mathbf{a}$ & {$[\mathbf{C l}] /[\mathrm{Br}]$} & $\mathbf{F}$ & $20,12^{[\mathrm{h}]}$ & 33,20 & $>99$ \\
17 & $\mathbf{3 b}$ & {$[\mathbf{C l}] /[\mathrm{Br}]$} & $\mathbf{F}$ & $25,18^{[\mathrm{h}]}$ & 42,30 & $>99$ \\
18 & $\mathbf{4}$ & {$[\mathbf{C l}] /[\mathrm{Br}]$} & $\mathbf{F}$ & $2,4^{[\mathrm{h}]}$ & 3,7 & $>99$ \\
\hline
\end{tabular}

[a] Reaction conditions: epoxide (5.0 mmol), Al-complex (0.002 mmol; 0.04 mol\%), nucleophile (Nu: $0.010 \mathrm{mmol} ; 0.2 \mathrm{~mol} \%)$, mesitylene $(1.0 \mathrm{mmol}), 10$ bar, $2 \mathrm{~h} ; \mathrm{Sub}=$ substrate, Sel. = diastereo-specificity, i.e. cis/trans ratio in the product. ND stands for not determined, $[\mathrm{Cl}]=\mathrm{PPNCl},[\mathrm{Br}]=\mathrm{TBAB}$. $[\mathrm{b}]$ Determined by ${ }^{1} \mathrm{H}$ NMR $\left(\mathrm{CDCl}_{3}\right)$ using mesitylene as internal standard, first number refers to yield when using $\mathrm{PPNCl}$; the average of two runs is reported. Selectivity towards the cyclic carbonates was $>99 \%$, stereoselectivity indicated is towards the trans ( 8 and $\mathbf{1 0})$ or cis $(\mathbf{9})$ product. [c] TON $=$ total turnover number observed per $\mathrm{Al}$; note that complex 2 contains two $\mathrm{Al}$ centers. [e] Total pressure was 15 bar, partial $\mathrm{CO}_{2}$ pressure was 10 bar. [f] Chemo-selectivity was $81 \%, 19 \%$ of diol product was formed. [g] Chemoselectivity was $91 \%, 9 \%$ of diol product was formed. [h] epoxide $(1.0 \mathrm{mmol})$ Al-complex (0.006 mmol; $0.12 \mathrm{~mol} \%)$, nucleophile $(0.030 \mathrm{~mol} ; 0.6 \mathrm{~mol} \%)$, $\operatorname{MEK}(0.5 \mathrm{~mL}), 2 \mathrm{~h}$ (for PPNCl) and $14 \mathrm{~h}$ (for TBAB). 
18, conversion $76 \%$, TON $=3800$ ) of all binary catalyst combinations.

Whereas the aminotriphenolate complexes 1a-1c in the presence of TBAB steadily increase their performance at higher reaction temperatures, from the date in Table 3 it is clear that the opposite trend is noted for the porphyrin based catalysts $\mathbf{3 a} / \mathbf{3 b}$ and the North system 2 (entries 21-23). The highest turnover number (3800) was noted for the binary catalyst $1 \mathrm{a} / \mathrm{TBAB}$ at $105^{\circ} \mathrm{C}$ among the series of catalyst systems tested. Similar order turnovers are reached with $\mathbf{3 a}$ (3500) or $\mathbf{3 b}$ (3300) when combined with $\mathrm{PPNCl}$ at $90^{\circ} \mathrm{C}$ (see Table 1). The reaction temperature is thus one of the decisive process parameters for selection of the most efficient catalyst system.

\section{Conversion of Internal Epoxides}

After examination of terminal epoxides $\mathbf{A}-\mathbf{C}$ as coupling partners for $\mathrm{CO}_{2}$ and observing clear trends for the reactivity of binary catalysts derived from complexes 1-4, we then turned our focus on the use of more challenging internal epoxides D-F (Table 4) and their conversion into cyclic carbonates 8-10 to see whether the reactivity and performance of the various binary catalyst systems would follow a similar tendency.

Interestingly, most of the features noted in the conversion of the terminal epoxides are maintained when using internal epoxides as substrates. The porphyrin based catalysts derived from $\mathbf{3} \mathbf{a} / \mathbf{3} \mathbf{b}$ and PPNCl typically give the highest conversions (and consequently TON values; $c f$. entries 5,11 and 17 ), whereas in the presence of TBAB the aminophenolate Al-complex 1a becomes more competitive displaying similar turnover numbers (entries 2, 8 and 14). However, apart from the similarities, there are also some other observations that add to the overall performance of the binary catalyst systems. For substrate D (trans-2,3-epoxybutane) the chemo-selectivity towards the cyclic carbonate was $>99 \%$ for all cases except for the binary catalysts $3 b / \mathrm{PPNCl}$ and $3 \mathrm{~b} / \mathrm{TBAB}$. For these systems there was significant formation of a diol product (rac-butane-2,3-diol) of up to $19 \%$ of the total amount of product formed. ${ }^{[22]}$ Also, the stereo-specificity was not quantitative in these cases, and loss of stereo-information was noted to be more pronounced when PPNCl was present ( $d r$ $=24: 76$, trans isomer major component). Therefore, despite the higher activity noted for $3 b / P P N C l$ and $3 b / T B A B$, the lower chemo-selectivity and stereo-specificity makes the binary system based on 1a the most attractive catalyst alternative.

The other two internal epoxides $\mathbf{E}$ (cyclopentene oxide) and $\mathbf{F}$ (trans-2,3-diphenyloxirane) gave rise to stereospecific conversions as expected since the cyclic carbonate products 9 and $\mathbf{1 0}$ are known to be exclusively formed with a preferred cis $(9)^{[23]}$ or trans (10) configuration. ${ }^{[24]}$ For the porphyrin-based binary catalysts based on $\mathbf{3 a}$ and $\mathbf{3} \mathbf{b}$ higher turnovers are again reached in the presence of $\mathrm{PPNCl}$ as additive (entries 10,11, 16 and 17). For the sterically most crowded substrate $\mathbf{F}$ the use of a smaller nucleophile $(\mathrm{Cl})$ is advantageous as much shorter time frames (PPNCl: $2 \mathrm{~h}$ cf. TBAB: $14 \mathrm{~h}$ ) are required for appreciable conversion. ${ }^{[25]}$ Upon changing to bromide as nucleophile, the binary system $1 \mathrm{a} / \mathrm{TBAB}$ provides higher conversion and turnover with respect to the porphyrin based catalysts $3 a / T B A B$ and
3b/TBAB (cf., entries 14, 16 and 17). However, overall the reactivity found with $3 a / P P N C l$ and $3 b / P P N C l$ stands out for the conversion of this particular substrate, in line with the turnover data observed when using cyclopentene oxide (E).

\section{Mechanistic Considerations}

The initial activities here determined for all binary catalysts based on Al-complexes 1-4 using terminal (A-C) and internal epoxides (D-F) demonstrate a number of interesting features. First, higher activities are generally achieved when aminotriphenolate $\mathrm{Al}$-complexes $\mathbf{1 a - 1 c}$ and the North complex 2 are combined with TBAB; however, the binary catalysts based on 1a-1c show significantly higher reactivities at relatively low complex loadings $(0.01 \mathrm{~mol} \%$ for the terminal epoxide conversions, $0.04-0.60 \mathrm{~mol} \%$ in case of the internal epoxides).

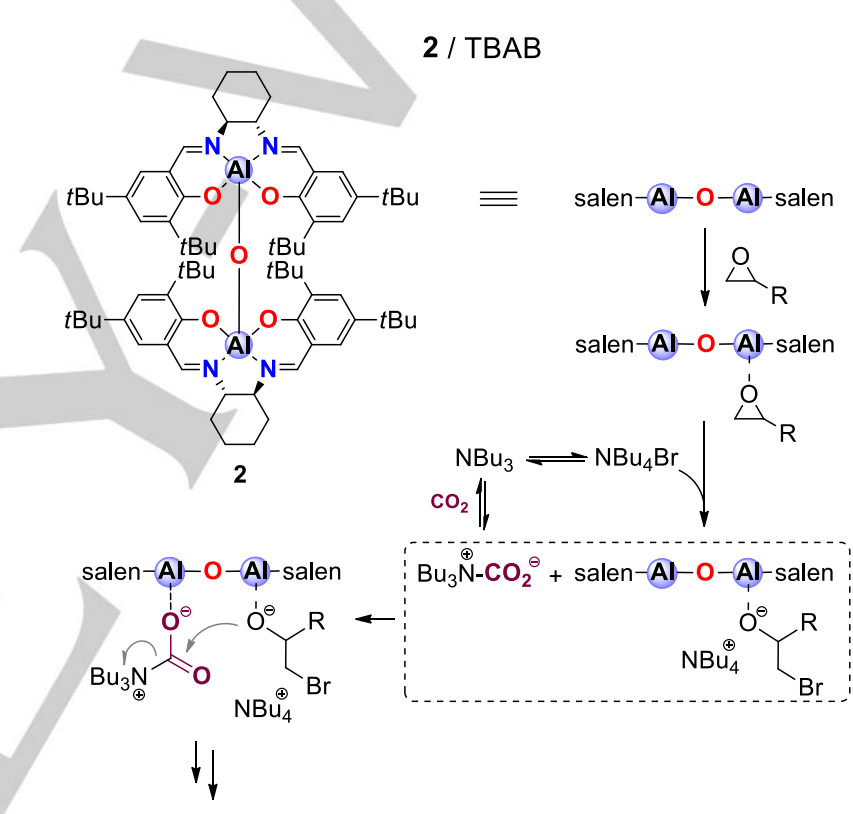

cyclic carbonate

\section{Only 2}
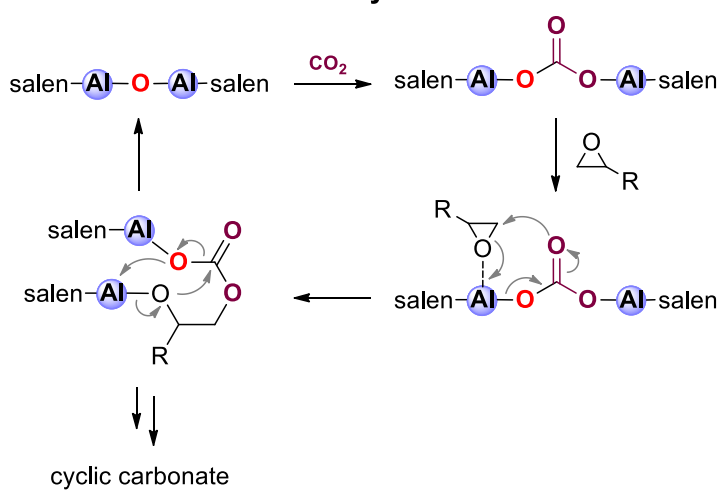

Scheme 1. Part of the reported mechanistic manifolds reported for the binary catalyst $2 / T B A B$ and 2 alone. 
At ambient temperature $\left(25^{\circ} \mathrm{C}\right)$ the conversion of 1,2 epoxyhexane mediated by $2 /$ TBAB works most efficiently and shows comparable turnover/Al center as observed for 1a-1c in the presence of the same nucleophile. However, both types of catalyst systems show clear opposite temperature effects. The North catalyst shows decreased turnovers whereas the aminotriphenolate complexes perform better at higher reaction temperature with turnover numbers of up to $3800 / \mathrm{h} / \mathrm{Al}$ center. These results seem to be in line with the reported mechanisms for the aminotriphenolate complex $\mathbf{1} \mathrm{a}^{[15 \mathrm{c}]}$ and North complex $\mathbf{2}^{[26]}$ in the conversion of epoxides and $\mathrm{CO}_{2}$ into cyclic carbonates.

The mechanism proposed by North et al. (Scheme 1) ${ }^{[26 a, b]}$ revealed a second order dependence on TBAB, meaning that catalysis mediated by the binary combination 2/TBAB should be sensitive towards the loading of TBAB, and particularly slowed down at low concentration of the nucleophile. The loadings of complex 2 (0.01-0.04 mol\%) and TBAB (0.05-0.20 mol\%) were rather low (apart from those used for substrate $\mathbf{F}$ ) throughout the studies performed here as compared to the much higher loadings reported in the literature (typically $1.0-2.5 \mathrm{~mol} \%$ for 2 and 2.5 mol\% for TBAB). ${ }^{[26 b]}$ Therefore, it is not surprising that initial catalytic turnover at these lower loadings was rather modest.

Another important aspect is that both Al centers in $\mathbf{2}$ are not exceptionally Lewis acidic and recent work ${ }^{[26 c]}$ revealed that 2 itself in the absence of TBAB preferably acts as a Lewis base rather than a Lewis acid, activating $\mathrm{CO}_{2}$ via the bridging oxygen atom to form an interesting carbonate-bridging $\mathrm{Al}_{2}$-complex. This alternative pathway starts off with $\mathrm{CO}_{2}$ insertion into the $\mathrm{Al}-\mathrm{O}-\mathrm{Al}$ bond, followed by epoxide activation through coordination to one of the metal centers. Subsequent intramolecular cyclization then affords the cyclic carbonate product. In both mechanisms, the activation of an epoxide by the $\mathrm{Al}_{2}$-complex 2 is weak, and therefore reactions performed at higher reaction temperatures and at lower loading of $\mathbf{2}$ should increase the dynamics of this coordinative interaction. This results in a much lower population of the epoxide-activated intermediate, slowing down the catalytic transformation as was indeed observed experimentally.

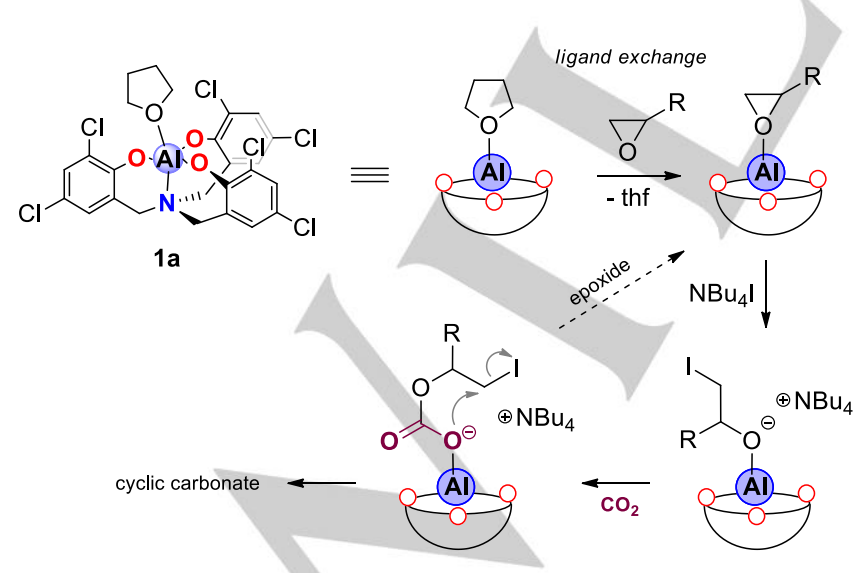

Scheme 2. Part of the reported mechanism mediated by the binary catalyst 1a/TBAI.
As opposed to $2 /$ TBAB the activity for the binary couple $1 \mathrm{a} / \mathrm{TBAB}$ increases at higher reaction temperatures. Previously the mechanism operative for a similar binary couple (1a/TBAl; Scheme 2) was investigated in detail by DFT and the initial ligand exchange was confirmed by X-ray analysis. ${ }^{[15 c]}$ These studies revealed that initial formation of an epoxide-ligated complex occurs with a free energy change of $-9.9 \mathrm{kcal} / \mathrm{mol}$ (substrate was propylene oxide), thus demonstrating the favorable Lewis acidic character of the metal center. Compared to 2 forming a hexacoordinated intermediate with the epoxide substrate, 1a exchanges a THF molecule (see Figure 1, Scheme 2) for an epoxide and initially remains five-coordinate, and simply forms a thermodynamically more stable coordination complex. At higher reaction temperatures it is expected that the axial coordination site in the trigonal bipyramidal coordination sphere remains occupied by an epoxide substrate despite a faster ligand exchange rate with bulk epoxide. Therefore, the observation of faster turnover for $1 \mathrm{a} / \mathrm{TBAB}$ (Table 3 ) at higher reaction temperatures is in line with this prediction, and the Lewis acidity for 1a plays thus a dominant role in this mechanism. Beside the Lewis acidity, in order to create the most powerful binary combination, a bromide would be preferred over chloride nucleophile since bromide has a higher nucleophilic character and better leaving group ability in the ring-opening and ringclosing step, respectively. This is indeed noted in the results of Tables 1, 2 and 4 for substrates A-E; only in the case of a high degree of steric crowding in the epoxide (i.e., trans-2,3diphenyloxirane $\mathbf{F}$ ), chloride-based nucleophiles are providing a better alternative as steric features at the epoxide ring-opening stage dominate.

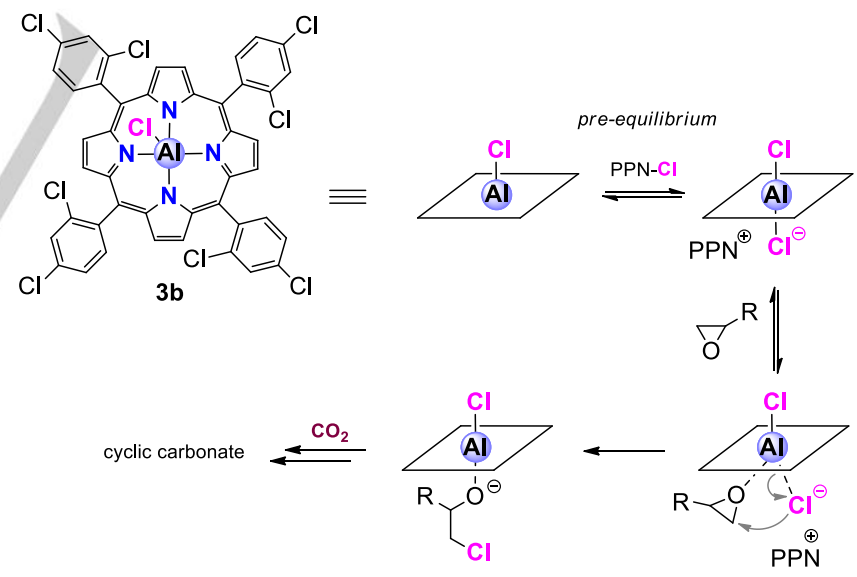

Scheme 3. Proposed mechanism mediated by the binary catalyst $3 b / P P N C l$ based on literature data and experimental findings herein.

The porphyrin based binary catalysts derived from $\mathbf{3 a}$ and $\mathbf{3 b}$ in general show fairly similar results in terms of initial rates in the conversion of epoxide substrates $\mathbf{A}-\mathbf{F}$, and thus it seems that here the porphyrin substitution does not play a decisive role. More importantly, these $\mathrm{Al}$ (porphyrin)s show the highest activity when combined with PPNCl, and do not follow the typical reactivity trend observed for many binary catalysts comprising of halide 
nucleophiles. The fact that also for the porphyrins $\mathbf{3 a}$ and $\mathbf{3 b}$ combined with TBAB at high reaction temperature $\left(105^{\circ} \mathrm{C}\right.$, Table 3) lower turnover numbers are observed seems to suggest the occurrence of a pre-equilibrium (Scheme 3). Al(porphyrin)s have been previously shown to form hexa-coordinated species when combined with nucleophilic additives including DMAP (4dimethylaminopyridine), azides and chloride salts. ${ }^{[27]}$

Table 5. Comparison of the reactivities of binary Al-catalysts $1 \mathrm{a} / \mathrm{Nu}$ and $3 \mathbf{a} / \mathrm{Nu}(\mathrm{Nu}=\mathrm{TBAB}, \mathrm{PPNCl})$ in the conversion of propylene oxide $\mathbf{C}$ into cyclic carbonate $\mathbf{5}$ at different metal-to-nucleophile ratios. ${ }^{[a]}$

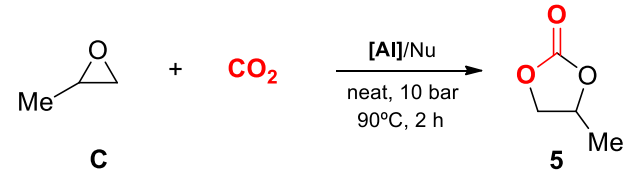

\begin{tabular}{|c|c|c|c|c|c|}
\hline Entry & Cat & $\mathrm{Nu}$ & ratio $\mathrm{Nu} / \mathbf{A l}$ & Yield $[\%]^{[b]}$ & $\operatorname{TON}^{[c]}$ \\
\hline 1 & - & PPNCl[d] & - & 4 & - \\
\hline 2 & - & PPNCII ${ }^{[e]}$ & - & 5 & - \\
\hline 3 & - & $\left.\mathrm{TBAB}\right|^{[\mathrm{d}]}$ & - & 3 & - \\
\hline 4 & - & $\left.\mathrm{TBAB}\right|^{[\mathrm{e}]}$ & - & 4 & - \\
\hline 5 & $1 a$ & TBAB & $5: 1$ & 32 & 16.1 \\
\hline 6 & $1 a$ & TBAB & $120: 1$ & 14 & 7.0 \\
\hline 7 & $1 a$ & $\mathrm{PPNCl}$ & $5: 1$ & 26 & 13.0 \\
\hline 8 & $1 a$ & $\mathrm{PPNCl}$ & $120: 1$ & 7 & 3.5 \\
\hline 9 & $3 b$ & TBAB & $5: 1$ & 38 & 19.1 \\
\hline 10 & $3 b$ & TBAB & $120: 1$ & 33 & 16.6 \\
\hline 11 & $3 b$ & $\mathrm{PPNCl}$ & $5: 1$ & 32 & 16.1 \\
\hline 12 & $3 b$ & $\mathrm{PPNCl}$ & $120: 1$ & 41 & 20.6 \\
\hline
\end{tabular}

[a] Propylene oxide (28.6 mmol), Al-complex (0.00057 mmol; $0.002 \mathrm{~mol} \%$ ), nucleophile ( $\mathrm{Nu}: 0.069 \mathrm{mmol}$ or $0.0029 \mathrm{mmol} ; 0.24$ or $0.01 \mathrm{~mol} \%$ ), mesitylene $(1.0 \mathrm{mmol}), 15 \mathrm{bar}, 90^{\circ} \mathrm{C} ; 1: 5[\mathrm{Al}] / \mathrm{Nu}$ ratios for $18 \mathrm{~h}, 1: 120[\mathrm{Al}] / \mathrm{Nu}$ ratios for $0.5 \mathrm{~h}$. [b] Determined by ${ }^{1} \mathrm{H}$ NMR $\left(\mathrm{CDCl}_{3}\right)$ using mesitylene as internal standard; the average of two runs is reported. Selectivity towards propylene carbonate was $>99 \%$. [c] TON = total turnover number $\left(\times 10^{3}\right)$ observed per Al center. [d] Blank reaction using 0.0029 mmol Nu, 18 h. [e] Blank reaction using $0.069 \mathrm{mmol} \mathrm{Nu}, 0.5 \mathrm{~h}$.

Importantly, the copolymerization of propylene oxide (PO) and $\mathrm{CO}_{2}$ can be mediated by a Al(porphyrin)/PPNCl combination. The reaction was found to be first order in $[\mathrm{Al}]$ and the nucleophilic ring-opening of the coordinated epoxide was suggested to occur on the same face of the porphyrin scaffold. According to the Pearson acid base concept, ${ }^{[28]}$ a hard Lewis acid (the Al-complex) binds more strongly with hard ligands such as chloride than with softer donors such as bromide or iodide. Such a behavior would therefore increase the probability for epoxide ring-opening occurring at a di-chloro-Al(III)porphyrin anion, facilitating the formation of the cyclic carbonate. Therefore, the experimental findings reported in Tables 1, 2 and 4 follow agreeably this envisioned trend.Also, at $105^{\circ} \mathrm{C}$ and lower catalyst loading $(0.02$ $\mathrm{mol} \%[\mathrm{Al}])$ the relative rate increase for epoxide conversion compared to $1 \mathrm{a} / \mathrm{TBAB}$ is attenuated (see Table 3 ), which may be caused by a more dynamic chloride coordination to $\mathbf{3 b}$.

Darensbourg reported on the use of $\mathrm{Al}$ (salen) complexes such as 4 (see Figure to Table 1) combined with $\mathrm{NBu}_{4} \mathrm{X}$ as binary catalysts for the copolymerization of cyclohexene oxide $(\mathrm{CHO})$ and $\mathrm{CO}_{2}{ }^{[29]}$ Significantly higher copolymerization activities were obtained using salen ligands equipped with electron-withdrawing substituents that resulted in more electrophilic Al complexes. Thus, it is reasonable to assume that the bimetallic North catalysts 2 and $\mathrm{Al}$ (salen) complex $\mathbf{4}$ having peripheral electron-donating tert-butyl groups are not Lewis acidic enough to give high relative activity for cyclic carbonate formation at comparatively low loadings of $[\mathrm{Al}]$. This trend is essentially observed in the conversion of all terminal and internal epoxides $\mathbf{A}-\mathbf{F}$, and complexes $\mathbf{2}$ and $\mathbf{4}$ give generally the lowest catalytic efficiencies among the binary combinations, apart from the reactions carried out at $25^{\circ} \mathrm{C}$ using 1,2-epoxyhexane $\mathbf{A}$ as substrate (Table 3 ).

The two most efficient catalyst systems at low loading of [Al] and nucleophile (i.e., $\mathbf{1 a}$ and $\mathbf{3 b}$ ) were then evaluated in the synthesis of propylene carbonate (PC) using propylene oxide (PO) $\mathbf{C}$ as substrate (Table 5). Previously the porphyrin catalyst 3b displayed very high turnover numbers of $>100.000$ in short time frames $(0.5 \mathrm{~h})$ for the coupling of $\mathrm{PO}$ and $\mathrm{CO}_{2}$ at $120^{\circ} \mathrm{C} / 3.0$ $\mathrm{MPa}$ using PPNCl as nucleophilic additive. ${ }^{[11 \mathrm{c}]}$ Thus, we decided to benchmark the performance of $\mathbf{1 a}$ and $\mathbf{3 b}$ under similar conditions using this specific substrate,$^{[30]}$ and investigated the influence of the relative loading of the halide on the overall performance. Both $\mathbf{1 a}$ and $\mathbf{3 b}$ were combined with TBAB and PPNCl in different ratios (1:5 and 1:120) in standard autoclave reactors. The conversion was determined after a pre-set time interval, i.e. $0.5 \mathrm{~h}$ for the reactions performed with a $1: 120[\mathrm{Al}] / \mathrm{Nu}$ ratio, and $18 \mathrm{~h}$ for those reactions performed with 1:5 combinations of Al-complex and nucleophile. In all cases a clear positive effect of the addition of the Al-complex on the total conversion of $\mathrm{PO}$ into PC was noted, as the blank experiments in the absence of the Al-complexes gave much lower conversion (entries 1-4).

Interestingly, under these more dilute conditions the relative performance of complex 1a is improved and high turnovers are achieved in the presence of 5 equiv. of TBAB or PPNCl (entries 5 and 7 ; TON up to $\left.16.1 \times 10^{3}\right)$. When the relative loading of TBAB or PPNCl is increased (120 equiv., entries 6 and 8 ), however, a sharp decrease in overall performance is noted which seems to suggest that a too large excess of halide additive may result in competition for coordination to the Al center and thus block turnover of the epoxide substrate. This seems to be in line with the reported mechanism for $1 \mathrm{a} / \mathrm{TBAl},{ }^{[15 \mathrm{c}]}$ where initial epoxide coordination to the metal center is a key step towards the formation of the cyclic carbonate.

The porphyrin binary catalysts based on $\mathbf{3 b}$, however, do not show this trend, and effectively at higher PPNCl loading (120 equiv.) the catalytic performance is further improved (cf., entries 10 and 12) with a significantly higher turnover $\left(20.6 \times 10^{3}\right)$ reported under these conditions. This results also aligns well with 
the mechanistic proposal that an initial equilibrium exists where the $\mathrm{Al}$ (porphyrin) $\mathrm{Cl}$ coordinates a chloride anion before it interacts with the epoxide substrate to facilitate its ring-opening (Scheme 3). All together, the data presented in Table 5 illustrates that both 1a and $\mathbf{3 b}$ provide highly active binary catalysts under dilute conditions, and result in high turnover numbers in the conversion of $\mathrm{PO}$ into $\mathrm{PC}$ at different $[\mathrm{Al}] / \mathrm{Nu}$ ratios. ${ }^{[31]}$

\section{Conclusions}

Herein we have described the detailed comparison between a series of Al-based binary catalysts derived from complexes 1-4 and their (initial) efficiencies to mediate the coupling between various terminal and internal epoxides, and $\mathrm{CO}_{2}$ to produce their corresponding cyclic carbonates. Under more dilute catalysis conditions using low loadings of $[\mathrm{Al}]$ and $[\mathrm{Nu}]$ while fixing their relative ratio (1:5), the binary catalysts $1 a / T B A B$ and $3 b / P P N C l$ display the highest reactivities among all the binary combinations tested, a trend that was observed for all substrates tested $(\mathbf{A}-\mathbf{F})$; in the conversion of highly sterically crowded trans-2,3diphenyloxirane, however, the use of a chloride-based nucleophile is more beneficial.

These studies also demonstrate that benchmarking studies ${ }^{[30]}$ are vital to provide insight into the relative reactivities of binary catalyst systems, and to determine the best operating window (temperature, metal-to-nucleophile ratio, solvent, scale) for each individual catalyst. The known mechanistic manifolds for epoxide conversion into cyclic carbonate can be used a directing blueprints to select the most appropriate catalyst system depending on the reaction temperature, the nature of the substrate (focusing on chemo-selectivity, cf. conversion of substrate $\mathbf{D}$ in Table 4) and the accessibility of the catalyst structures. The latter feature can be of high importance in those cases where scale up of the catalytic process is desired and larger quantities of catalyst are thus required.

Detailed benchmarking studies for similar type binary catalysts such as described in this work offer a way to compare performance metrics under identical reaction conditions and to unravel intrinsic and relative reactivities. These benchmarking approaches are essential to support general claims on catalyst performance in a wider context, thereby stimulating careful assessment of other considerations that are also important to select the most appropriate catalyst for $\mathrm{CO}_{2}$ conversion. ${ }^{[31]}$

\section{Experimental Section}

General catalytic procedure
The respective epoxide, Al-complex, co-catalyst (PPN-Cl, TBAB or TBAI) and internal standard (mesitylene) were charged into a stainless steel autoclave. The autoclave was then sealed and heated to the required temperature while stirring. After reaching the selected reaction temperature, the autoclave was pressurized with $\mathrm{CO}_{2}$ to the desired pressure and left stirring. At the end of the chosen time interval, the autoclave was cooled to rt and then carefully depressurized. An aliquot of the reaction mixture was taken for analysis and the conversion was determined by ${ }^{1} \mathrm{H}$ NMR spectroscopy in $\mathrm{CDCl}_{3}$. The identities of the cyclic carbonate products were confirmed by comparison to literature data. For specific details on the used (parallel) reactor systems, their volumes and amount of substrates, Al complexes and additives, see the Supporting Info (SI). Details concerning the Al-complexes used in this work and their characterization are provided in the SI.

\section{Acknowledgements}

We thank ICIQ, ICREA, and the Spanish Ministerio de Economía y Competitividad (MINECO) through project CTQ-2014-60419-R and the Severo Ochoa Excellence Accreditation 2014-2018 through project SEV-2013-0319. JR thanks ICIQ for a predoctoral fellowship.

Keywords: aluminum $\cdot$ benchmarking $\cdot$ carbon dioxide $\cdot$ cyclic organic carbonates $\cdot$ homogeneous catalysis

[1] For some general reviews on $\mathrm{CO}_{2}$ valorization/conversion: a) J. Klankermayer, S. Wesselbaum, K. Beydoun, W. Leitner, Angew. Chem. Int. Ed. 2016, 55, 7296-7343; b) Q. Liu, L. Wu, R. Jackstell, M. Beller, M. Nat. Commun. 2015, 6, 5933; c) N. Kielland, C. J. Whiteoak, A. W. Kleij, A. W. Adv. Synth. Catal. 2013, 355, 2115-2138; d) M. Cokoja, C. Bruckmeier, B. Rieger, W. A. Herrmann, F. E. Kühn, Angew. Chem. Int. Ed. 2011, 50, 8510-8537; e) X.-B. Lu, D. J. Darensbourg, Chem. Soc. Rev. 2012, 41, 1462-1484; f) B. Yu, L.-N. He, ChemSusChem 2015, 8, 52-62; g) C. Maeda, Y. Miyazaki, T. Ema, Catal. Sci. Technol. 2014, 4, 1482-1497.

[2] For descriptive contributions relating to $\mathrm{CO}_{2}$ chemistry and utilization: a) M. Aresta, A. Dibenedetto, A. Angelini, Chem. Rev. 2014, 114, 17091742; b) M. Peters, B. Köhler, W. Kuckshinrichs, W. Leitner, P. Markewitz, T. E. Müller, ChemSusChem 2011, 4, 1216-1240; c) E. A. Quadrelli, G. Centi, J.-L. Duplan, S. Perathoner, ChemSusChem 2011, 4, 1194-1215, d) M. Aresta, Carbon Dioxide as Chemical Feedstock, Wiley-VCH, Weinheim, Germany, 2010.

[3] Earlier accounts on the use of epoxides as coupling partners for $\mathrm{CO}_{2}$ : a) A.-A. G. Shaik, S. Sivaram, Chem. Rev. 1996, 96, 951-976; b) M. North, R. Pasquale, C. Young, Green. Chem. 2010, 12, 1514-1539; c) T. Sakakura, J.-C. Choi, H. Yasuda, Chem. Rev. 2007, 107, 2365-2387; d) A. Decortes, A. M. Castilla, A. W. Kleij, Angew. Chem. Int. Ed. 2010, 49, 9822-9837.

[4] For some examples using hydrogen as a reducing agent in the synthesis of $\mathrm{MeOH}$ and/or formic acid from $\mathrm{CO}_{2}$ : a) W.-H. Wang, Y. Himeda, J. T. Muckerman, G. F. Manbeck, E. Fujita, Chem. Rev. 2015, 115, 1293612973; b) W. Wang, S. Wang, X. Ma, J.Gong, Chem. Soc. Rev. 2011, 40, 3703-3727; c) G. A. Olah, A. Goeppert, S. G. K. Prakash, Beyond Oil and Gas: The Methanol Economy, Wiley-VCH, Weinheim, Germany, 2009.

[5] A. Tlili, E. Blondiaux, X. Frogneux, T. Cantat, Green Chem. 2015,17, 157-168. 
[6] For recent reviews on cyclic carbonates: a) C. Martín, G. Fiorani, A. W. Kleij, ACS Catal. 2015, 5, 1353-1370; b) J. W. Comerford, I. D. V. Ingram M. North, X. Wu, Green Chem. 2015, 17, 1966-1987; c) G. Fiorani, W Guo, A. W. Kleij, Green Chem. 2015, 17, 1375-1389; d) P. P. Pescarmona, M. Taherimehr, Catal. Sci. Technol. 2012, 2, 2169-2187.

[7] a) A. Tullo, Chem. Eng. News 2008, 86, 21-22; b) W. J. Peppel, Ind. Eng. Chem. 1958, 50, 767-770. For general information about the application potential of COCs: c) B. Schäffner, F. Schäffner, S. P. Verevkin, A Börner, Chem. Rev. 2010, 110, 4554-4581.

[8] a) A. Decortes, A. M. Castilla, A. W. Kleij, Angew. Chem. Int. Ed. 2010 49, 9822-9837; b) C. J. Whiteoak, A. W. Kleij, Synlett 2013, 24, 1748 1756. See also references $6 a, b, d$.

[9] For a recent review on the use of organocatalysis in COC formation see: M. Cokoja, M. E. Wilhelm, M. H. Anthofer, W. A. Herrmann, F. E. Kühn, ChemSusChem 2015, 8, 2436-2454. See also reference 6c.

[10] For recent examples of new enantio-, diastereo- or regioselective approaches towards or using COCs see: a) W. Guo, V. Laserna, E. Martin, E. C. Escudero-Adán, A. W. Kleij, Chem. Eur. J. 2016, 22, 17221727 ; b) S. Sopeña, V. Laserna, W. Guo, E. Martin, E. C. Escudero-Adán A. W. Kleij, Adv. Synth. Catal. 2016, 358, 2172-2178; c) V. Laserna, G. Fiorani, C. J. Whiteoak, E. Martin, E. Escudero-Adán, A. W. Kleij, Angew. Chem. Int. Ed. 2014, 53, 10416-10419; d) Y. Liu, W.-M. Ren, K.-K. He, W.-Z Zhang, W.-B. Li, M. Wang, X.-B. Lu, J. Org. Chem. 2016, 81, 89598966.

[11] Highly (re)active systems: a) C. J. Whiteoak, N. Kielland, V. Laserna, E. C. Escudero-Adán, E. Martin, A. W. Kleij, J. Am. Chem. Soc. 2013, 135, 1228-1231; b) T. Ema, Y. Miyazaki, S. Koyama, Y. Yano, T. Sakai, Chem Commun. 2012, 48, 4489-4491; c) Y. Qin, H. Guo, X. Sheng, X. Wang, F. Wang, Green Chem. 2015, 17, 2853-2858; d) J. Qin, P. Wang, Q. Li Y. Zhang, D. Yuan, Y. Yao, Chem. Commun. 2014, 50, 10952-10955; e) F. Della Monica, S. V. C. Vummaleti, A. Buonerba, A. De Nisi, M. Monari, S. Milione, A. Grassi, L. Cavallo, C. Capacchione, Adv. Synth. Catal. 2016, 358, 3231-3243. Recently a binary organocatalyst was reported that showed initial turnover frequencies of up to $500 / \mathrm{h}$, see: f) $\mathrm{L}$. Martínez-Rodríguez, J. Otalora Garmilla, A. W. Kleij, ChemSusChem 2016, 9, 749-755; g) J. A. Castro-Osma, K. J. Lamb, M. North, ACS Catal. 2016, 6, 5012-5025.

[12] For some recent relevant examples: a) G. L. Gregory, L. M. Jenisch, B. Charles, G. Kociok-Köhn, A. Buchard, Macromolecules 2016, 49, 7165 7169; b) F. Auriemma, C. de Rosa, M. Rosaria Di Caprio, R. di Girolamo W. Chadwick Ellis, G. W. Coates, Angew. Chem. Int. Ed. 2014, 54, 12151218; c) L. Peña Carrodeguas, J. González-Fabra, F. Castro-Gómez, C. Bo, A. W. Kleij, Chem. Eur. J. 2015, 21, 6115-6122; d) C. Martín, A. W Kleij, Macromolecules 2016, 49, 6285-6295; e) O. Hauenstein, M. Reiter S. Agarwal, B. Rieger, A. Greiner, Green Chem. 2016, 18, 760-770.

[13] Fe-based catalysis: a) A. Buonerba, A. De Nisi, A. Grassi, S. Milione, C. Capacchione, S. Vagin, B. Rieger, Catal. Sci. Technol. 2015, 5, 118-123 b) C.J. Whiteoak, E. Martin, E. Escudero-Adán, A.W. Kleij, Adv. Synth. Catal. 2013, 355, 2233-2239; c) C. J. Whiteoak, E. Martin, M. Martínez Belmonte, J. Benet-Buchholz, A. W. Kleij, Adv. Synth. Catal. 2012, 354 469-476; d) A. Buchard, M. R. Kember, K. G. Sandeman, C. K. Williams, Chem. Commun. 2011, 47, 212-214; e) M. Adolph, T. A. Zevaco, C Altesleben, O. Walter, E. Dinjus, Dalton Trans. 2014, 43, 3285-3296; f) M. A. Fuchs, T. A. Zevaco, E. Ember, O. Walter, I. Held, E. Dinjus, M. Döring, Dalton Trans. 2013, 42, 5322-5329.

[14] Zn-based catalysis: a) J. Hu, J. Ma, Q. Zhu, Q. Qian, H. Han, Q. Mei, B. Han, Green Chem. 2016, 18, 382-385; b) M. A. Fuchs, C. Altesleben, S. C. Staudt, O. Walter, T. A. Zevaco, E. Dinjus, Catal. Sci. Technol. 2014 4, 1658-1673; c) Y. Ren, J. Chen, C. Qi, H. Jiang, ChemCatChem 2015, 7, 1535-1538; d) A. Decortes, A. W. Kleij, ChemCatChem 2011, 3, 831834; e) A. Decortes, M. Martínez Belmonte, J. Benet-Buchholz, A. W. Kleij, Chem. Commun. 2010, 46, 4580-4582.

[15] Al-based catalysis: a) D. Tian, B. Liu, Q. Gan, H. Li, D. J. Darensbourg, ACS Catal. 2012, 2, 2029-2035; b) M. North, S. C. Z. Quek, N. E. Pridmore, A. C. Whitwood, X. Wu, ACS Catal. 2015, 5, 3398-3402; c) C.
J. Whiteoak, N. Kielland, V. Laserna, F. Castro-Gómez, E. Martin, E. C. Escudero-Adán, C. Bo, A. W. Kleij, Chem. Eur. J. 2014, 20, 2264-2275 d) J. Martínez, J. A. Castro-Osma, A. Earlam, C. Alonso-Moreno, A. Otero, A. Lara-Sánchez, M. North, A. Rodríguez-Diéguez, Chem. Eur. J. 2015, 21, 9850-9862; e) M. Cozzolino, K. Press, M. Mazzeo, M. Lamberti, ChemCatChem 2015, 8, 455-460; f) M. North, S. C. Z. Quek, N. E. Pridmore, A. C. Whitwood, X. Wu, ACS Catal. 2015, 5, 3398-3402.

[16] a) T. Ema, Y. Miyazaki, J. Shimonishi, C. Maeda, J.-Y. Hasegawa, J. Am. Chem. Soc. 2014, 136, 15270-15279; b) C. Maeda, T. Taniguchi, K. Ogawa, T. Ema, Angew. Chem. Int. Ed. 2015, 54, 134-138.

[17] C. Maeda, J. Shimonishi, R. Miyazaki, J.-Y. Hasegawa, T. Ema, Chem. Eur. J. 2016, 22, 6556-6563.

[18] As far as we know, benchmarking studies such as detailed herein have not been reported in the literature, and we are aware of only one similar study where several hydrogen-bond donor type organocatalysts have been compared in the coupling of $\mathrm{PO}$ and $\mathrm{CO}_{2}$, see: M. Alves, B. Grignard, S. Gennen, R. Mereau, C. Detrembleur, C. Jerome, T. Tassaing, Catal. Sci. Technol. 2015, 5, 4636-4643.

[19] Initial reactivities were examined at $90^{\circ} \mathrm{C}$ as both the Kleij and Wang/Qin systems have previously been studied at these elevated temperatures showing high turnover, see references $11 \mathrm{a}, 11 \mathrm{c}$ and $15 \mathrm{c}$

[20] Note that we here preferably used PPNCl and not TBAC (tetrabutylammonium chloride) as the latter is much more hygroscopic and thus more difficult to handle when using minimal amounts of reagents.

[21] F. Castro-Gomez, G. Salassa, A.W. Kleij, C. Bo, Chem. Eur. J. 2013, 19, 6289-6298.

[22] The formation of a diol product was independently checked and confirmed by comparison with the ${ }^{1} \mathrm{H}$ NMR spectrum of an authentic sample.

[23] Previous work from the Darensbourg group has experimentally and computationally shown that the formation of cyclopentene carbonate trans-9 is thermodynamically not feasible due to a high level of ring strain see: a) D. J. Darensbourg, A. D. Yeung, Macromolecules 2013, 46, 8395; b) D. J. Darensbourg, A. D. Yeung, S.-H. Wei, Green Chem. 2013 15, 1578-1583.

[24] The cis-carbonate $\mathbf{1 0}$ has been reported by reacting an appropriate diol precursor with $\mathrm{CO}_{2} / \mathrm{BuBr}$ mediated by excess $\mathrm{DBU}(\mathrm{DBU}=, 8$ diazabicyclo[5.4.0] undec-7-ene), see: a) T. Kitamura, Y. Inoue, T. Maeda, J. Oyamada, Synth. Commun. 2016, 46, 39-45; See also: b) M. A. Casadei, S. Cesa, M. Feroci, A. Inesi, New J. Chem. 1999, 23, 433436. However, as far as we know, the formation of the trans carbonate $\mathbf{1 0}$ from the pure trans epoxide $\mathbf{F}$ is typically quantitative because of the higher ring strain in the cis carbonate product: c) C. Beattie, M. North, P. Villuendas, C. Young, J. Org. Chem. 2013, 78, 419-426. See also references $11 \mathrm{a}, 11 \mathrm{e}, 11 \mathrm{~g}, 13 \mathrm{~b}$ and 17.

[25] The catalysis data obtained with substrate $\mathbf{F}$ seems to suggest that for sterically hindered internal epoxide conversion chloride nucleophiles become competitive alternatives, and the nucleophilic ring-opening of the epoxide is more easily facilitated by these weaker though smaller nucleophiles.

[26] Mechanistic details for the binary catalysts based on 2/TBAB $(25 a+b)$ and 2 only (25c), respectively: a) M. North, R. Pasquale, Angew. Chem. Int. Ed. 2009, 48, 2946-2948; b) W. Clegg, R. W. Harrington, M. North R. Pasquale, Chem. Eur. J. 2010, 16, 6828-6843; c) J. A. Castro-Osma, M. North, W. K. Offermans, W. Leitner, T. E. Müller, ChemSusChem 2016, 9, 791-794.

[27] C. Chatterjee, M. H. Chisholm, Inorg. Chem. 2011, 50, 4481-4492.

[28] R. G. Pearson, J. Am. Chem. Soc. 1963, 85, 3533-3539.

[29] Donald J. Darensbourg, D. R. Billodeaux, Inorg. Chem. 2005, 44, 1433 1442

[30] Note that the scale of the reaction (28.6 mmol of PO) was significantly higher in these cases compared to the results reported in Tables 1-4, which can positively influence the gas/liquid phase equilibrium for the $\mathrm{CO}_{2}$ reagent. Consequently, higher turnover numbers may be obtained. 
[31] A comparison of catalysts 1a (Kleij), 2 (North) and $\mathbf{3 b}$ (Wang and Qin) and the cost of their synthesis is provided in the Supporting Information, Tables S1-S3. From this general comparison, the use of complex 1a versus 2 and $\mathbf{3 b}$ seems attractive as the cost (per mmole) is (significantly) lower, whereas the synthetic difficulty towards the preparation of all three Al complexes is fairly similar in terms of total steps involved (two) and the use of a pyrophoric Al-reagent upon metalation of the ligand structure. Alternatively, when sustainable conditions are specifically pursued (low or ambient temperature/pressure), the somewhat higher cost of catalyst $\mathbf{3 b}$ is offset by its high activity at $25^{\circ} \mathrm{C}$, see Table 3 . However, since catalyst $\mathbf{3 b}$ works significantly better in the presence of $\mathrm{PPNCl}$ (being more expensive than TBAB), the type of nucleophile should also be a determining factor in the choice for a suitable catalyst. 


\section{Entry for the Table of Contents}

\section{FULL PAPER}

Take a pick: The reactivities of a small series of binary catalysts derived from various combinations of Al complexes and nucleophiles have been examined. These benchmarking studies provide a useful comparison of their overall performances in the coupling of both terminal and internal epoxides, and $\mathrm{CO}_{2}$ to afford their cyclic carbonates. The results are explained from a mechanistic point of view, and the crucial role of the nucleophile, its amount and catalyst concentration are discussed.
Jeroen Rintjema and Arjan W. Kleij"

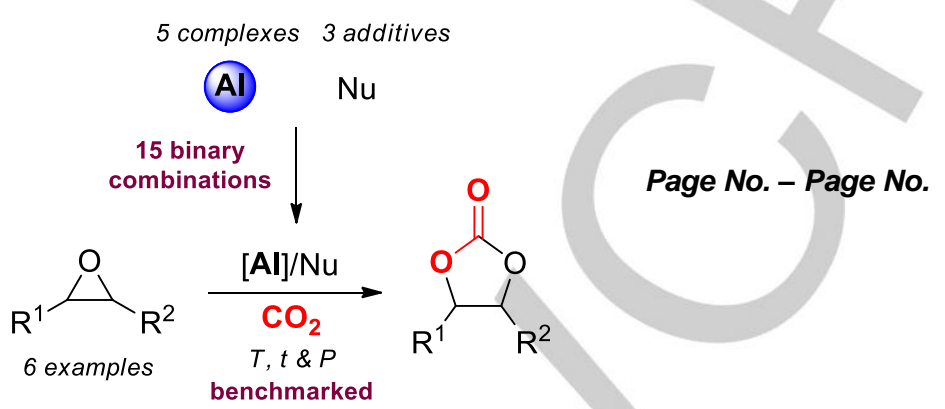

Aluminium-Mediated Formation of Cyclic Carbonates: Benchmarking Catalytic Performance Metrics 